\title{
Study of MODIS derived AOD at three different locations in the Indo Gangetic Plain: Kanpur, Gandhi College and Nainital
}

\author{
P. Choudhry, A. Misra, and S. N. Tripathi \\ Department of Civil Engineering, Indian Institute of Technology, Kanpur-208016, India \\ Correspondence to: S. N. Tripathi (snt@iitk.ac.in) \\ Received: 5 September 2011 - Revised: 21 August 2012 - Accepted: 3 September 2012 - Published: 5 October 2012
}

\begin{abstract}
Moderate resolution imaging spectroradiometer (MODIS) sensors, onboard Terra and Aqua, have been observing the Earth since start of 2000 and mid 2002, respectively. The present study provides a comparison of Collection 5 (C005), aerosol optical depth (AOD) retrieved by MODIS, with AERONET-observed AOD over Kanpur (an urban site), Gandhi College (a rural site) and Nainital (a relatively clean site) in the Indo Gangetic Plain (IGP). The results show that at Kanpur, MODIS retrievals are well within the prelaunch uncertainty $\pm 0.05 \pm 0.15 \tau$, and a good correlation $\left(R^{2}>0.7\right.$ for both Terra and Aqua). Nainital also shows good retrieval $\left(R^{2}>0.8\right.$ for Terra and $R^{2}>0.68$ for Aqua), as more than $66 \%$ of total collocations are within the prelaunch uncertainty. However, it is seen that there is significant overestimation in this case, especially in the months of winter. Gandhi College poses a challenge to MODIS retrieval, as here $<57 \%$ of MODIS-retrieved AOD values lay within the prelaunch uncertainty and the correlation is very poor $\left(R^{2} \sim 0.5\right.$ for Aqua and $R^{2} \sim 0.4$ for Terra); also there is persistent underestimation in this case. Small value of slope shows that assumed model results in underestimation, and large intercept values for the linear regression fit show that errors due to surface reflectance are high here. Our comparison shows that MODIS retrieval works well over Kanpur, and Nainital with winter as an exception. However, MODIS retrieval is poor for Gandhi College which is a rural area. The aerosol properties at Kanpur are currently used as representative of the entire subcontinent in the MODIS C005 algorithm, which is not an accurate assumption. The large variability in land use and climate over India makes it a site too complex for a single aerosol model to be used over the entire area. Therefore further study with as many sites as possible over the Indian subcontinent would help provide more realistic modeling for the Indian subcontinent.
\end{abstract}

Keywords. Atmospheric composition and structure (Aerosols and particles)

\section{Introduction}

Aerosols are small (sub-micron to several-micron) suspended particles in the atmosphere. Their origin may be either anthropogenic or natural (Seinfeld and Pandis, 1998). They are a major component of our environment and play a very crucial role in the global climate system (Solomon et al., 2007; Charlson et al., 1992). Aerosols have a direct and indirect effect on the global climate. They can absorb or scatter the incoming solar and terrestrial radiation, with the amount of radiation scattered or absorbed depending on the optical and chemical properties of the aerosols. The radiation, scattered and absorbed, affects the earth's radiation budget and thus modulates the heating or cooling of the Earth.

Accurate estimation of the radiative effect of aerosols requires knowledge of their optical and physical properties (Tripathi et al., 2005a). Aerosols have a short lifetime and thus a very strong spatial and temporal variation is seen in their concentration. Remotely-sensed data enables us to quantitatively determine the aerosol optical properties and thus determine global aerosol budget (King et al., 1999; Bellouin et al., 2005). Ground-based observation is a point measurement and therefore cannot account for spatial variation unless a large network is operational. Satellite retrieval provides large data coverage owing to the large swath size. However, satellite measurements are based on certain assumptions. Ground-based data have no such constraint, and therefore provide the microphysical and optical properties of the ambient columnar aerosols with high accuracy. In addition, 
they provide the means for validating the satellite-measured aerosol properties (Kaufman et al., 1997a).

The launch of MODIS (Moderate Resolution Imaging Spectroradiometer) onboard Aqua and Terra was a major step in the remote sensing of aerosol optical properties over land. They provide data products that are used globally to study aerosol climatology and as input to various models in order to determine the radiative heat transfer (King et al., 1992). Its wide swath size of $2330 \mathrm{~km}$ and large spectral coverage (36 bands) make it highly suitable for characterization of aerosol properties (Levy et al., 2010; King et al., 2003). Efficient retrieval algorithms have been developed in order to make use of the MODIS sensitivity to aerosol signals. These algorithms are constantly improved and updated as and when new information with regard to the aerosol type and input parameters (e.g. surface reflectance) are available.

The C005 algorithm of MODIS simultaneously inverts information about spectral reflectance contained in $0.47 \mu \mathrm{m}$, $0.66 \mu \mathrm{m}$ and $2.12 \mu \mathrm{m}$ channels. Initially the $2.12 \mu \mathrm{m}$ channel was assumed transparent, but the $\mathrm{C} 005$ assumes that this channel contains information on coarse mode aerosol. Inversion yields three primary parameters, the aerosol optical depth $(\tau)$ at $0.55 \mu \mathrm{m}$, the non-dust or fine weighting $(\eta)$, and the surface reflectance at $2.12 \mu \mathrm{m}$. Also, aerosol optical depth at $0.47 \mu \mathrm{m}$ and $0.66 \mu \mathrm{m}$ is provided as a result of retrieval. Retrievals of negative $\tau$ values (up to -0.05 ) are allowed to balance the statistics of $\tau$ in low $\tau$ conditions (Levy et al., 2007).

The validation and evaluation of any retrieved data product is very important to establish its quality and suitability to be used in climatological or weather modeling. It is required that the dataset be within a certain level of uncertainty with regards to the "ground truth". The primary means of MODIS validation is by showing that a product matches equivalent observations from AERONET or other similar accurate systems. For example, it is required that at least $2 / 3$ of global matched pairs (e.g. MODIS versus AERONET) must be contained within the envelope of expected uncertainty to be considered validated (Levy et al., 2005). Using this strategy, the C004 $\tau$ products were validated (i.e. V4.2 and before) and were matched within the envelopes of Eqs. (1) and (2) over ocean and land, respectively (Remer et al., 2005). It was found that the retrievals were well within the prelaunch uncertainty for both ocean (Eq. 1) and land (Eq. 2).

$\Delta \tau= \pm 0.03 \pm 0.05 \tau$.

$\Delta \tau= \pm 0.05 \pm 0.15 \tau$

The global evaluation and validation of C005, MODIS darktarget aerosol products, shows that the product has high correlation $(R=0.9)$ and reduction in errors that have been achieved with better assumptions made about surface types, aerosol model and the inclusion of polarization in the computation of top of atmosphere (TOA) reflectance in the C005 algorithm (Levy et al., 2010). But still it does not fall within the error envelope at every site. The biases have been related to local aerosol condition, observation geometry and the surface properties of a particular place which are not in agreement with the MODIS retrieval algorithm assumption (Levy et al., 2010). C005 is thus globally validated but still local biases need to be accounted for and the aerosol properties in the look-up table (LUT) for algorithm need to be updated for as many sites as possible in order to make the retrieved AOD more accurate (Levy et al., 2010).

The Indian subcontinent has high spatial and temporal variation in climate, land use and atmospheric conditions. A study using C004 (Tripathi et al., 2005a) was done over Kanpur $\left(26^{\circ} 28^{\prime} \mathrm{N}, 80^{\circ} 21^{\prime} \mathrm{E}\right)$ in 2004. A 2006 study with C005 (Jethva et al., 2007) over Kanpur in Northern India was again done to study the improvement in the retrieval for C005 over C004. Another study (Misra et al., 2008) using C005 over semiarid region of Ahmedabad $\left(23.03^{\circ} \mathrm{N}, 72.5^{\circ} \mathrm{E}\right)$ in Western India has been done in order to validate the MODIS retrieval over the Indian subcontinent. The current study illustrates the comparison between the MODIS-retrieved AOD with the AERONET stations at Kanpur, Gandhi College and Nainital. These three sites are entirely different with regard to aerosol climatology, land type, atmospheric condition, etc. (Srivastava et al., 2012). Kanpur is an extremely polluted and urban site (Tripathi et al., 2005b; Giles et al., 2011), Gandhi College (Srivastava et al., 2011) is a rural site, and Nainital (Dumka et al., 2011) is a relatively clean site. A regression analysis at all three sites, for both the sensors and at all three wavelengths $(0.47,0.55$ and $0.66 \mu \mathrm{m})$, has been done to validate the MODIS retrieval at these locations. A seasonal variability has also been studied in order to understand how the sensor aboard Terra and Aqua at these three channels performs under different weather conditions. This was followed by a detailed statistical analysis to gain further understanding of our results and the confidence in the calculated $R^{2}$.

\section{Site description}

The Indo-Gangetic Plain (IGP) encompasses a vast area, accounting for $\sim 21 \%$ of the land area of India. It is a densely populated region accommodating $\sim 40 \%$ of the Indian population. Fast growing economy and increasing population have burdened this region, resulting in a wide range of anthropogenic activities. A large number of thermal power plants, most of them coal fed, are clustered along this region (Nair et al., 2007). The IGP continuously produces anthropogenic pollution from urban, industrial, and rural combustion sources. In addition, it is affected by convection-induced winds driving desert and alluvial dust into the atmosphere during the pre-monsoon season (Dey et al., 2004; Remer et al., 2008). The mixing of natural and anthropogenic aerosols results in complex microphysical and chemical properties, 
which show a very strong seasonal variation (Tripathi et al., 2005a; Eck et al., 2010; Dey and Tripathi, 2008).

\subsection{Kanpur}

Kanpur $\left(26^{\circ} 28^{\prime} \mathrm{N}, 80^{\circ} 21^{\prime} \mathrm{E}\right)$ is located in the IGP in Northern India. It is one of the biggest industrial hubs of Northern India. Being near the banks of river Ganga, agriculture is also practiced in the nearby areas. The city is highly polluted as a result of heavy industrialization and a population of nearly 4.5 million per census report 2011 . Sulfates, nitrates and other industrial pollutants are present in abundance at Kanpur (Sharma et al., 2003). The region experiences variable winds from north westerly to south westerly, as observed in the data from the local weather station (Tripathi et al., $2005 \mathrm{~b}$ ). The dust storms in the month of pre-monsoon further alter the local aerosol condition, and foggy condition prevails in the area during the winter season (Baxla et al., 2009; Tripathi et al., 2006). The land use is almost consistent within the urbanized area, while the outer agriculture practicing areas have variability in land use. This variation in land use affects the ground reflectance, which is the main reason for error in retrieved AOD by MODIS. This is discussed in detail in the following sections. The Indian Institute of Technology, which is the location of AERONET station for Kanpur, is nearly $17 \mathrm{~km}$ from the city.

\subsection{Gandhi College}

The site is located at Ballia $\left(25^{\circ} \mathrm{N}, 84^{\circ} \mathrm{E}\right)$ in the IGB region at a distance $466 \mathrm{~km}$ east of Kanpur. It is a rural site in the eastern part of IGP with moderate climate. Rivers Ganga and Ghaghara frequently flood the area, making it highly fertile due to deposition of rich alluvial soil. Most of the land is under cultivation, leading to variable land use in this region per season. This makes the retrieval of AOD from satellites more complex than for an urban site like Kanpur, where land use is almost consistent. In rural areas, bio-fuels such as fuel wood, dung cake and crop waste, predominantly contribute to aerosol formation (Habib et al., 2006). In addition, the region has a lot of biomass burning, especially in the winter months.

\subsection{Nainital}

Nainital $\left(29^{\circ} 23^{\prime} \mathrm{N}, 79^{\circ} 27^{\prime} \mathrm{E}\right)$ has an average elevation of 2084 meters (6837 feet) in the central Himalayas (Dumka et al., 2008, 2011). Farther to the west lie densely populated regions, including the Indian capital (New Delhi); the southern region includes the heavily populated Gangetic plains. AERONET is stationed at Manora peak with the hilly terrain of the central Himalayan ranges $(\sim 2.0 \mathrm{~km}$ m.s.l. $)$ northeast of the peak. The region has essentially no industrial activities and is rather clean. However, pollutants are transported from the valley beneath with a strong diurnal cycle. The site, being relatively clean, helps us in quantifying the performance of MODIS under low aerosol loading. The region experiences snowfall from December to February, and thus provides grounds for analyzing the precision of snow-masking by the MODIS C005-L algorithm.

\section{Data}

The aerosol data from MODIS are provided at different levels per the processing scheme. AERONET too provides data at three levels: level 1.0 (unscreened), level 1.5 (cloudscreened) and level 2.0 (quality assured) (Holben et al., 1998). In the current study we have used the Collection 005-L of MODIS level 2 Aerosol product and AERONET level 2.0 data at all three sites. MODIS data from both Aqua and Terra satellites have been taken in order to study the diurnal variations. At Kanpur, the data have been taken from 2001 to 2010 for Terra and 2002 to 2010 for Aqua. At Gandhi College, data have been taken from 2006 to 2010 for both Terra and Aqua. At Nainital, the data have been taken from 2008 to 2010 for both the sensors.

\subsection{MODIS}

The current MODIS C005-L algorithm retrieves AOD by using only dark pixels. The "dark pixels" are identified using the reflectance for the channel $2.12 \mu \mathrm{m}\left(\rho_{2.12}\right)$ as $0.01 \leq$ $\rho_{2.12} \leq 0.25$. Amongst these, the brightest $50 \%$ and the darkest $20 \%$ as defined by $\rho_{0.66}$ are discarded, leaving a maximum of 120 pixels. The retrieval is based on transparency of aerosols in the mid-IR wavelengths (Kaufman et al., 1997b). The surface reflectance for dark pixels along with satellite and solar geometries are input to the algorithm. The measured reflectances in the visible channels are compared with the simulated values of top of atmosphere reflectance in the look-up table (LUT) (Remer et al., 2005). The look-up tables have been made using the data from AERONET and other resources. The algorithm identifies and discards the water, cloudy and snow/ice pixels at the initial stage. The aerosol model is decided per the location, and the ratio of path radiance in the visible infrared spectrum (VIS) (0.47 and $0.66 \mu \mathrm{m})$ channels.

The initial assumption of a constant ratio between VIS and $2.12 \mu \mathrm{m}$ channel (Kaufman et al., 1997b) has been improved to incorporate variations with season and scattering angle. In the MODIS C005 algorithm, the improved VIS to $2.12 \mu \mathrm{m}$ surface reflectance ratios make the retrieved product more accurate and realistic (Levy et al., 2005). The variability in the relationship per location, season and angle was studied (Levy et al., 2007; Gatebe et al., 2001; Remer et al., 2005, 2001 ) and it was inferred that a single set of VIS to $2.12 \mu \mathrm{m}$ ratios is not globally applicable. Relationship between VIS to $2.12 \mu \mathrm{m}$ reflectance is presented as a function of both surface type (Normalized Difference Vegetation Index - NDVI SWIR $_{\text {) }}$ and scattering angle $(\Theta)$ (ATBD-2009). 


$$
\text { NDVISWIR }_{\text {SW }}=\left(\rho_{1.24}^{m}-\rho_{2.12}^{m}\right) /\left(\left(\rho_{1.24}^{m}+\rho_{2.12}^{m}\right) .\right.
$$

The current algorithm also brings in the concept of polarization in the radiative transfer calculation. The C004 algorithm used the non-polarized (scalar) calculation in the radiative transfer code (Dave, 1970). But this was not very accurate since, under certain geometry, neglecting the polarization in the radiative transfer calculation could lead to significant error in top of atmosphere reflectance, and consequently even greater error in the retrieved $\tau$ (Levy et al., 2005, 2004). A polarized radiative transfer code RT3 (Evans and Stephens, 1991 ) is currently used to calculate top of atmosphere reflectance and total fluxes that are stored in the LUT.

The MODIS data for all three sites are downloaded and then collocated with the corresponding AERONET data for each site. This is done by taking the spatial average of MODIS-retrieved AOD over the AERONET site. To get the MODIS AOD corresponding to a particular AERONET location, the AOD values from pixels lying in $\pm\left(1 / 4^{\circ}\right)$ of latitude and longitude of that station are extracted from the entire data file of a particular day. At least 10 pixels are needed for a collocation to be included in our statistics. The spatial averaging is then done for all these AODs for a given day. A table storing the spatially averaged AOD along with the date and time of retrieval is prepared, to be further used in the analysis.

\subsection{AERONET}

The AERONET measurement and retrieval algorithm provides various aerosol properties by direct sun measurements of spectral AOD and the use of multiangular and multispectral measurements of sun radiance (Dubovik and King, 2000; Holben et al., 1998; Dubovik et al., 2000, 2006). Unlike MODIS, AERONET does not suffer from errors due to the ground reflectance and aerosol type assumptions. Thus it can provide highly accurate information on aerosol parameters specific to that site. The accuracy of AOD measured by AERONET is $\sim 0.01$ in visible and near infrared and $\sim 0.02$ in the ultraviolet range (Eck et al., 1999).

AOD data are downloaded from AERONET website (http: //aeronet.gsfc.nasa.gov/cgi-bin/webtool_opera_v2_new). The time of overpass for MODIS at each site is used for temporal collocation of the AERONET data. A time window of $\pm 30 \mathrm{~min}$ with respect to MODIS overpass (centre of this time window) is taken, and a temporal average of AERONET-retrieved AOD is done (Ichoku et al., 2002). Further AERONET data are taken only when there are at least 2 out of possible 5 retrievals in the given time window (Levy et al., 2010).

AERONET does not give AOD values corresponding to the three wavelengths for MODIS-retrieved AOD. Quadratic fits on log-log scale for wavelength vs. AOD is done to interpolate AERONET data to MODIS band-effective wavelengths (Eck et al., 1999). The final data are then used for linear regression analysis. Diurnal variation is studied using data from both Terra and Aqua. The data are also classified into seasons for all 3 wavelengths and at all three sites. This is done in order to study the effect of seasonality in the retrieval quality of MODIS, varying between different types of locations. The classification into seasons is done as winter (December-February), pre-monsoon (March-May), monsoon (June-August) and post-monsoon (September-November) (Tripathi et al., 2005a).

\section{Results and discussion}

The obtained spatiotemporal data statistics for AOD $_{\text {MODIS }}$ and $\mathrm{AOD}_{\text {AERONET }}$ help in identifying the uncertainties in the retrieval. The difference in magnitude of AOD at different stations helps us to study the variation in local aerosol loading. The current study uses the spatial-temporal collocated data for three different sites, which are located in the IGP, and have totally different aerosol environments (urban, rural and relatively clean site). The three sites also differ in land use, thus having different surface reflectances. The seasonal behavior of aerosols also differs as is reflected in the regression results as well.

\subsection{Time series}

A time series depicting the variation in the monthly average values of AOD as retrieved by AERONET is shown in Fig. 1a. The monthly averaged AOD is computed using the AERONET data that are temporally collocated with MODIS (both Aqua and Terra) overpass for the $0.55 \mu \mathrm{m}$ channel.

The $\mathrm{x}$-axis represents the months; 1 stands for January 2001, and so on till December 2010. Kanpur shows AOD varying mostly from 0.2 to 0.8 . AOD values higher than 0.8 are seen in the 17th and 18th month (May and June 2002) and 54th month (June 2005). Dust storms are frequent in the IGP during the pre-monsoon months. The high dust loading during the dust period results in increase of AOD by $50 \%$ (Dey et al., 2004). The sudden rise in AOD during this season can be a result of the dust storms. The general trend of AOD across a year is shown to be decreasing through the months of winter up to pre-monsoon; increasing through months of premonsoon up to monsoon; decreasing through the months of monsoon up to post-monsoon; and finally increasing through the months of post-monsoon up to winter. December however shows an increase in AOD values. The aerosol properties observed over Kanpur are strongly wavelength dependent (SSA decreases with wavelength) during the winter season because of the dominance of urban (absorbing in nature) aerosols (Singh et al., 2004). Biomass burning further adds to the local aerosol loading. It has been observed that coldest season, i.e. winter, has the peak concentration for absorbing organic carbon (Arola et al., 2011). An increase in the AOD 

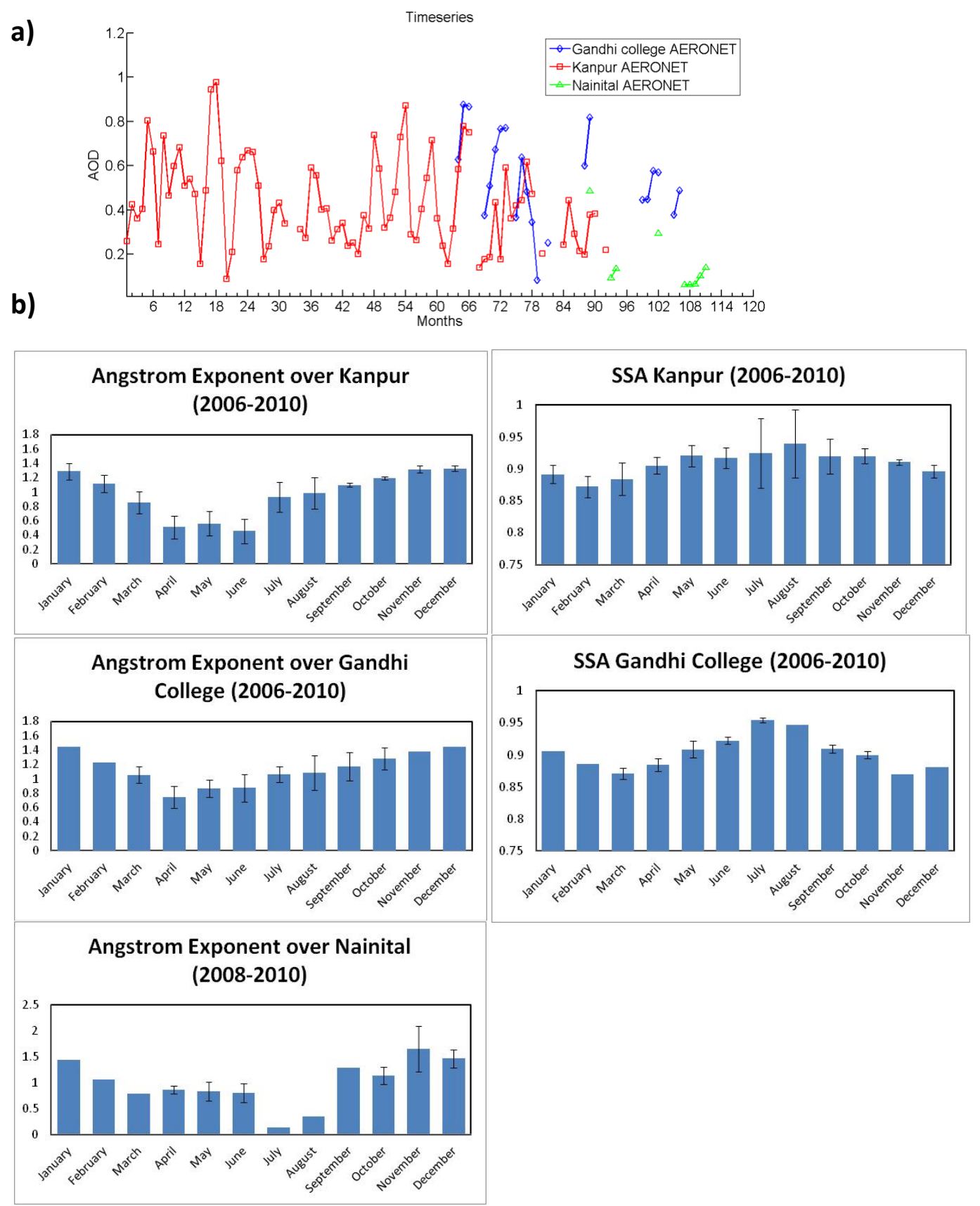

Fig. 1. (a) Time series plot of monthly average AOD (for $\lambda=0.55 \mu \mathrm{m}$ ) at Kanpur, Gandhi College and Nainital. X-axis describes the entire time period of study. The first month is January 2001 and the last is December 2010. (b) Angstrom exponent at Kanpur, Gandhi College (2006-2010), and Nainital (2008-2010), and SSA at Kanpur and Gandhi College (2006-2010).

during December is possibly a result of increased loading due to biomass burning.

Similar to Kanpur, AOD data of Gandhi College show an increase during the pre-monsoon months. However, the AOD values are higher than for Kanpur during this season in the months of April and May. Increase in AOD is seen during the post-monsoon months, and again the AOD is higher than Kanpur for the months of September 2005 to January 2006.
Not much data are available for winter and monsoon months to make any conclusive remarks. Post-monsoon and premonsoon show higher monthly average AOD values with respect to Kanpur, while the data from monsoon season show lower value for April 2006 to January 2007.

Nainital has collocated data for 9 months out of the study period of 2008-2010. Data being scattered over this duration do not allow us to make a strong conclusion about the 

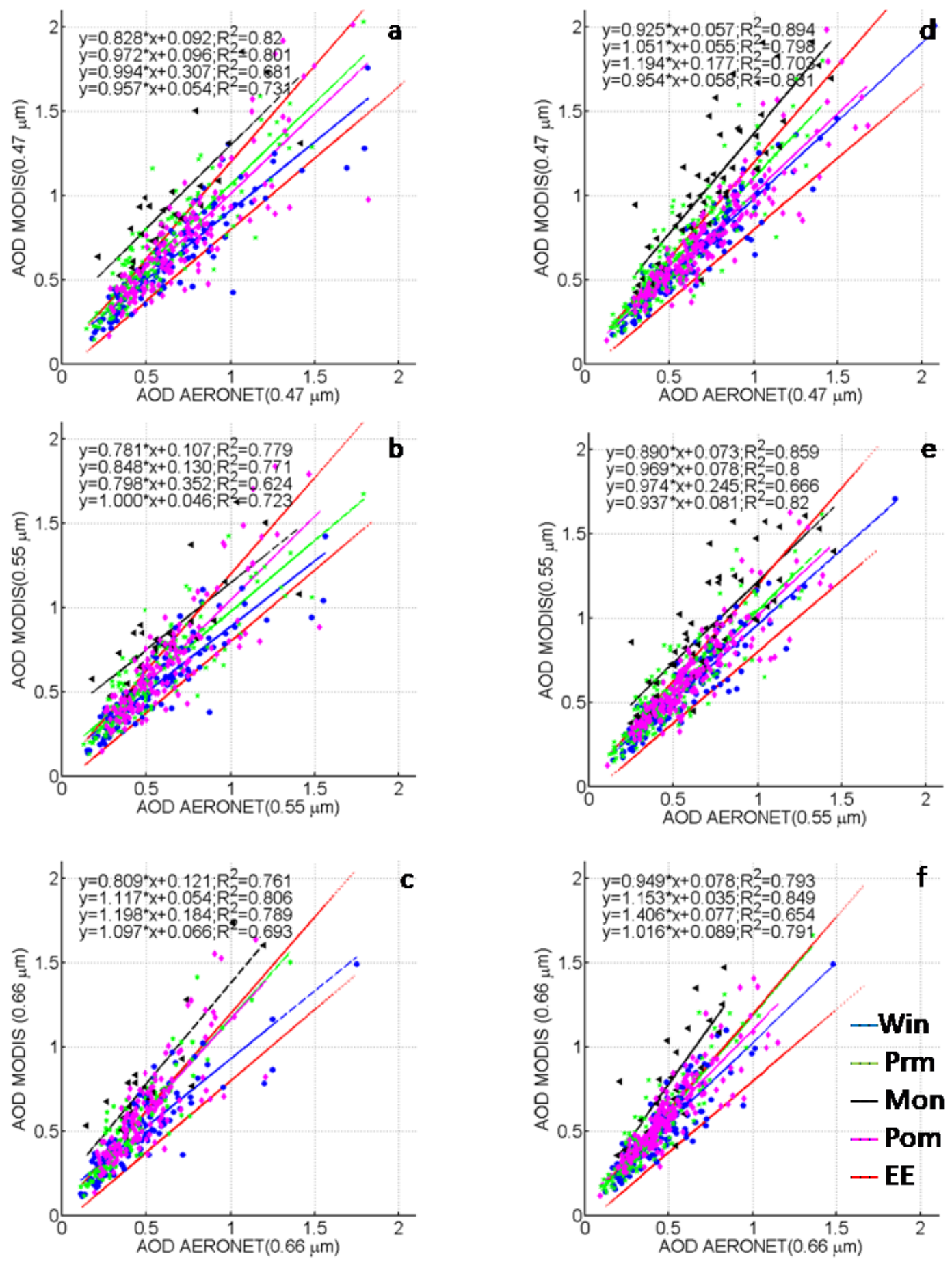

Fig. 2. MODIS-retrieved AOD versus AERONET at Kanpur for Aqua (a to c) and Terra (d to f), at $\lambda=0.475,0.55$ and $0.66 \mu \mathrm{m}$. Regression equations are in sequence winter (Win), pre-monsoon (Prm), monsoon (Mon) and post-monsoon (Pom). EE refers to the error envelope per the MODIS uncertainty of $\pm 0.05 \pm 0.15 \tau$, where $\tau$ is AOD.

seasonal changes in AOD, annually and inter-annually. As seen in the time series, data are present in continuous fashion during November 2009 to March 2010. They show an increasing trend in AOD but the values are significantly lower (AOD $<0.4$ mostly) than both Kanpur and Gandhi College.
In order to understand the differences between the sites, especially Kanpur and Gandhi College, both of which lie in the plains of Indo-Gangetic Basin, we have examined the Angstrom exponent and single scattering albedo (SSA) at these sites (Fig. 1b). Compared over the same 
period 2006-2010, the Angstrom exponent value at Kanpur shows large variation than Gandhi College (at Kanpur: $\mathrm{AE}_{\min }=0.25, \mathrm{AE}_{\max }=1.39$; at Gandhi College: $\mathrm{AE}_{\min }=$ $\left.0.58, \mathrm{AE}_{\max }=1.44\right)$. Thus, the amplitude of variation in $\mathrm{AE}$ at Kanpur is much larger than at Gandhi College. The corresponding variation at Nainital (for 2008-2010) is between $\mathrm{AE}_{\min }=0.13$ and $\mathrm{AE}_{\max }=1.97$. Averaged over the 5 year period, it is seen that the value of Angstrom exponent at Gandhi College is higher than Kanpur for all seasons - the difference being more pronounced for March to June period. Differences are also seen in the SSA characteristics at Kanpur and Gandhi College, when compared for the same period 2006-2010. Over Kanpur, SSA remains mostly nearly or above 0.9, except January, February and March. However, similar values at Gandhi College are seen only during January, and May to October. Thus, variations are less in SSA at Kanpur as compared to Gandhi College. Further, except January and February and monsoon months of July and August, SSA at Gandhi College is lower than or equal to that at Kanpur. These results show that the three sites have entirely different aerosol characteristics.

\subsection{Validation results}

Using the final collocated data (Spatially averaged MODIS AOD and temporally averaged AERONET AOD), regression analysis is performed for every site. The regression is performed on total data and seasonal data for all three wavelengths $(\lambda)(0.47,0.55$ and $0.66 \mu \mathrm{m})$. A seasonal spectral correlation analysis is performed in order to check how well the aerosol model assumed in the C005 algorithm over the IGB region of Indian subcontinent performs in the retrieval of AOD, and to find errors due to surface reflectance assumption specific to every site in the different seasons. The regression fit equation gives us information regarding both of the above conditions; the slope of equation shows how close the assumed aerosol model over a region is with regard to local aerosol type, and intercept gives us error due to surface reflectance (Hyer et al., 2011). The ideal condition would be to have slope $(m)$ as 1 and intercept $(c)$ as 0 . Deviation from these values shows bias in the retrieved AOD by MODIS. The value of $R^{2}$ gives us the percentage of variation in MODIS retrieval that can be explained by AERONET retrieval.

\subsubsection{Kanpur}

Earlier studies over Kanpur suggested that C004 product (for $\tau_{0.55}$ ) had a problem of overestimation in the pre-monsoon and monsoon period (Tripathi et al., 2005a). A later study using five year C005 data suggested that about $70 \%$ of MODIS retrieval at $0.47 \mu \mathrm{m}$ and $0.55 \mu \mathrm{m}$, and $60 \%$ at $0.66 \mu \mathrm{m}$, fall within the pre-launch uncertainty of MODIS AOD, and the correlation also improved as compared to C004 (Jethva et al., 2007).
The complete data regression shows that Terra has higher value of $R^{2}$ as compared to Aqua (Table 1). It is seen that $m \sim 1$ in all cases for Terra and the intercept is very small $(<0.075)$ for total data. Aqua however shows higher values for intercept as compared to Terra.

Figure 2 shows the regression plots with seasonal fits at Kanpur site for our study. A seasonal regression analysis is done in order to study the performance of the two sensors and also the retrieval quality at all three wavelengths $(\lambda)$ for different weather conditions. The regression coefficient is seen to be higher for Terra in all the seasons as compared to that of Aqua except for $0.47 \mu \mathrm{m}$ in pre-monsoon months and $0.66 \mu \mathrm{m}$ in monsoon. Considering $R^{2}$ first, we see that for winter and post-monsoon months, it decreases with increase in $\lambda$. This can be explained by the fact that during this period the dust loading is low and fine particles dominate (Dey et al., 2004), thus the smaller wavelength will be more sensitive and hence better correlation. Slope " $m$ " is high $(m>0.8$, except for $m_{0.55}=0.781$ ) for both Aqua and Terra in the winter months. The slope " $m$ " is nearly 1 in the post monsoon season for both sensors at all wavelengths $(\lambda)$. During winters Terra has smaller intercept values as compared to that of Aqua, and for both sensors reflectance problem is higher for the $0.66 \mu \mathrm{m}$ channel. Post-monsoon has lower error due to surface reflectance; Aqua has lower errors due to surface reflectance as compared to Terra during the post-monsoon months. A reverse trend in the $R^{2}$ is seen in the months of pre-monsoon. The $R^{2}$ values improve with increase in wavelength (with Aqua $0.55 \mu \mathrm{m}$ as an exception). This can be explained, as during this season higher dust loading is seen in the area due to incoming winds (Dey et al., 2004) and the presence of coarse aerosol results in better performance of the $0.66 \mu \mathrm{m}$ channel. No perfect trend in the values of " $m$ " or " $c$ " is seen in this season in either of the sensors, but here again slope $(m)$ is better and the intercept $(c)$ values are lower for Terra as compared to Aqua.

Classification of data in different seasons also helped in identifying the season with maximum outliers. It is found that the prominent outliers above the uncertainty envelope (or error envelope, EE) belong to monsoon, indicating cloud contamination during this season. The outliers lying below the uncertainty envelope represent cases of underestimation, or cases where AERONET measures very high AOD which are not reflected in MODIS data. Such cases happen "mostly" in local burning events. MODIS may lose such local events while averaging the $1 \mathrm{~km}$ resolution data to $10 \mathrm{~km}$. Winter thus contributes outliers in this region due to biomass burning prevalent during this season. Post-monsoon has outliers in both regions. It is because of the way we have defined seasons. In our study post-monsoon spans over September, October and November. September would still have cloud presence, providing outliers above the envelope, which is an overestimation. October witnesses heavy agricultural burning to prepare fields for next farming season, thus increasing the 
Table 1. Data statistics for Kanpur regression analysis. $m$ and $c$ are the slope and intercept for the linear regression fit, $R^{2}$ is the correlation coefficient, and $N$ is the total data points available. TOT: Total, WIN: Winter, PRM: Pre Monsoon, MON: Monsoon, POM: Post Monsoon.

\begin{tabular}{|c|c|c|c|c|c|c|c|c|}
\hline \multirow[b]{2}{*}{ TOT } & \multicolumn{4}{|c|}{ AQUA } & \multicolumn{4}{|c|}{ TERRA } \\
\hline & $m$ & $c$ & $R^{2}$ & $N$ & $m$ & $c$ & $R^{2}$ & $N$ \\
\hline 475 & 0.914 & 0.104 & 0.73 & 440 & 1.010 & 0.063 & 0.772 & 598 \\
\hline 550 & 0.883 & 0.109 & 0.717 & 440 & 0.975 & 0.073 & 0.788 & 598 \\
\hline 660 & 1.010 & 0.090 & 0.712 & 381 & 1.070 & 0.064 & 0.773 & 521 \\
\hline \multicolumn{9}{|l|}{ WIN } \\
\hline 475 & 0.828 & 0.092 & 0.82 & 111 & 0.925 & 0.058 & 0.894 & 137 \\
\hline 550 & 0.781 & 0.107 & 0.779 & 111 & 0.890 & 0.073 & 0.859 & 137 \\
\hline 660 & 0.809 & 0.121 & 0.761 & 109 & 0.949 & 0.078 & 0.849 & 137 \\
\hline \multicolumn{9}{|l|}{ PRM } \\
\hline 475 & 0.972 & 0.096 & 0.801 & 155 & 1.051 & 0.0554 & 0.798 & 228 \\
\hline 550 & 0.848 & 0.13 & 0.771 & 155 & 0.969 & 0.0781 & 0.8 & 228 \\
\hline 660 & 1.117 & 0.054 & 0.806 & 114 & 1.153 & 0.0351 & 0.849 & 175 \\
\hline \multicolumn{9}{|l|}{ MON } \\
\hline 475 & 0.994 & 0.307 & 0.681 & 26 & 1.194 & 0.177 & 0.703 & 51 \\
\hline 550 & 0.798 & 0.352 & 0.624 & 26 & 0.974 & 0.245 & 0.666 & 51 \\
\hline 660 & 1.198 & 0.184 & 0.789 & 20 & 1.406 & 0.077 & 0.654 & 27 \\
\hline \multicolumn{9}{|l|}{ POM } \\
\hline 475 & 0.959 & 0.0542 & 0.731 & 148 & 0.954 & 0.058 & 0.831 & 182 \\
\hline 550 & 1.000 & 0.0461 & 0.723 & 148 & 0.937 & 0.081 & 0.82 & 182 \\
\hline 660 & 1.097 & 0.0668 & 0.693 & 138 & 1.016 & 0.089 & 0.791 & 182 \\
\hline
\end{tabular}

concentration of absorbing aerosols. Thus outliers belonging to the month of October fall below the envelope.

In order to test the variation and reliability of $R^{2}$, a confidence level test was done. The analysis was done in order to check if the $R^{2}$ would have been different had the sample been different, i.e. to check the sample dependence of the results. It is seen that the $R^{2}$ values do not vary much even at a high confidence level $(99 \%)$ for total data. The results again show that Terra has higher reliability, as variation in the calculated $R^{2}$ is smaller $\left(\Delta R^{2} \sim 0.04\right)$ at a higher confidence level compared to Aqua. The seasonal data statistics show that variation is higher in Aqua as compared to Terra. Also, variation increases with increase in wavelength $(\lambda)$.

Nevertheless, the retrieval at Kanpur is well within the expected uncertainty and thus we can say that MODIS has good retrieval over Kanpur, for all wavelengths and during all seasons.

\subsubsection{Gandhi College}

The regression results of the total data show a very poor correlation between MODIS and AERONET-retrieved AOD values (Table 2). From the correlation coefficient it is seen that Aqua performs better than Terra, which is contrary to what is seen at Kanpur. It is also seen that for Aqua the correlation improves with increase in wavelength $(\lambda)$, but for Terra it follows the reverse trend, i.e. $R^{2}$ decreases with increase in wavelength. Such low values of slope $(m<0.66$, see Table 2) show that the aerosol type assumed is not very accurate and that there is considerable underestimation with respect to AERONET. Intercept " $c$ " is high, $\left(c_{\text {aqua }} \sim 0.1\right.$ and $c_{\text {terra }} \sim 0.2$ ), showing that MODIS has high error in retrieved AOD due to surface reflectance at Gandhi College. Spatial variation in surface reflectance at Gandhi College could be a reason for large scatter and bias in the scatter plots.

Figure 3 represents the regression plots for Gandhi College at all three wavelengths $(\lambda)$ for both the sensors, between AERONET and MODIS AOD. The seasonal regression result shows that the correlation is slightly better in winter months than for total data for Aqua, but for Terra it is very poor. Also for Aqua the $R^{2}$ worsens with increase in wavelength $(\lambda)$, as is seen in Kanpur, whereas for Terra the $R^{2}$ improves with increase in wavelength $(\lambda)$, contrary to Kanpur. The slope " $m$ " values for Aqua are significantly less than 1 for $0.66 \mu \mathrm{m}\left(m_{0.66}=0.43\right) ; 0.47 \mu \mathrm{m}$ and $0.55 \mu \mathrm{m}$ channels have better " $m$ " values amongst all seasons $(m>0.7)$. Terra has very poor $\mathrm{m}$ values at all $\lambda(m<0.31)$. Terra suffers more with errors due to surface reflectance during the winter months. Aqua also has a very high " $c$ " value mainly for $0.66 \mu \mathrm{m}$ channel $(c=0.185)$; the other two channels suffer less. This is expected considering that this season has dominance of fine particles and so lower $\lambda$ will show better performance. Pre-monsoon months also show same trend for Aqua with regard to the correlation, but for Terra it is seen that, unlike in winter, the correlation worsens with increase in wavelength $(\lambda)$. This is in contrast to what is seen in Kanpur for pre-monsoon where the correlation improved with increase in wavelength. Both Aqua and Terra have $m<0.6$ 

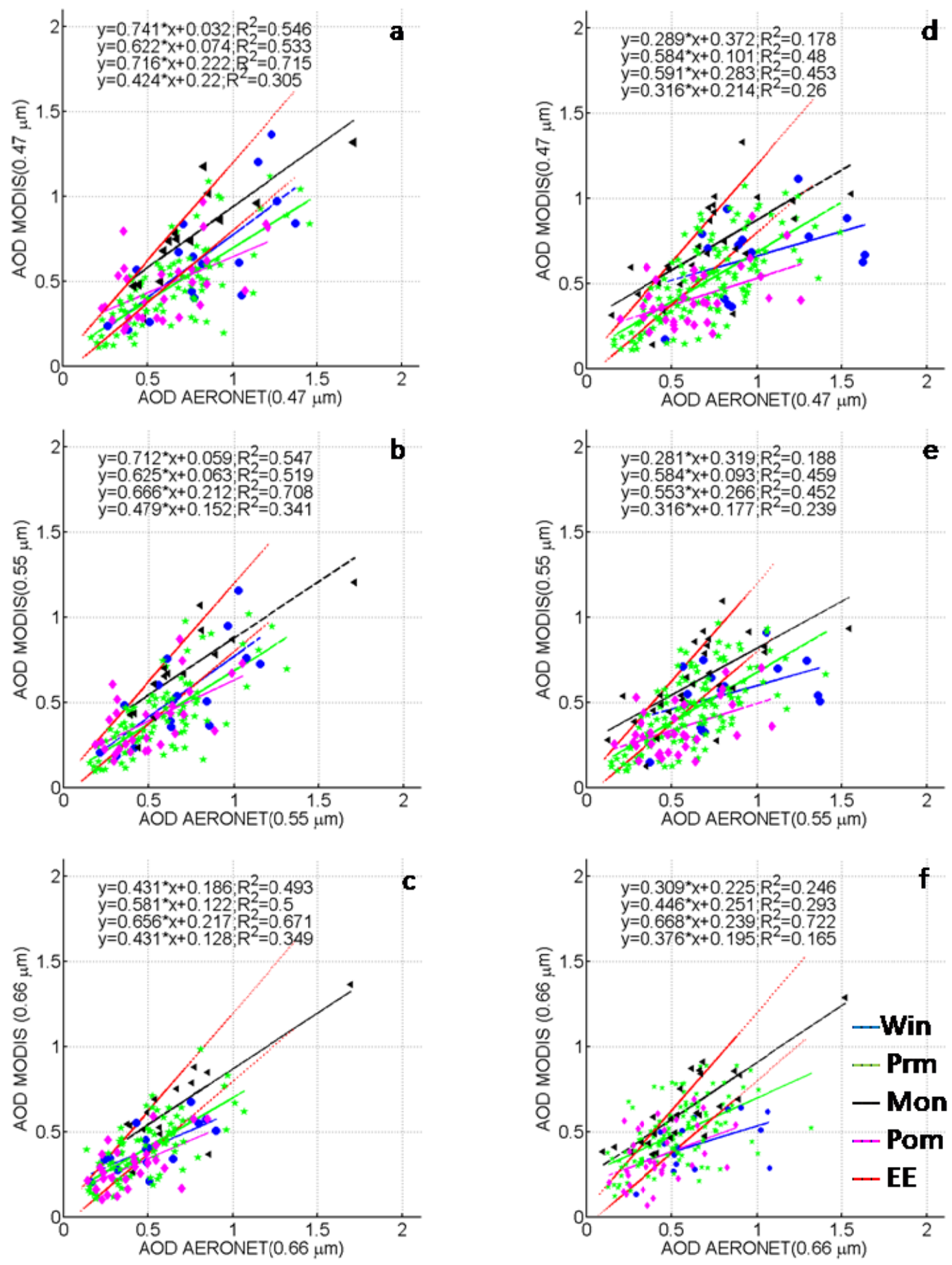

Fig. 3. MODIS-retrieved AOD versus AERONET at Gandhi College for Aqua (a to c) and Terra (d to f), at $\lambda=0.475,0.55$ and $0.66 \mu \mathrm{m}$. Regression equations are in sequence winter (Win), pre-monsoon (Prm), monsoon (Mon) and post-monsoon (Pom). EE refers to the error envelope per the MODIS uncertainty of $\pm 0.05 \pm 0.15 \tau$, where $\tau$ is AOD.

and $c$ is high $\left(c_{\min }=0.093\right)$. Here again $0.66 \mu \mathrm{m}$ channel has the highest " $c$ " value $\left(c_{\text {aqua }}=0.122\right.$ and $\left.c_{\text {terra }}=0.251\right)$ for both Aqua and Terra. The post-monsoon season shows poor correlation but here again Aqua performs relatively better. The slope is lowest in this season for Aqua, but still higher than Terra. The intercept is again high and decreases with the increase in wavelength for Aqua, which is again due to dominance of finer aerosols in this season. Kanpur (Aqua) and Gandhi College (Terra) have no set trend for interceptwavelength dependence. Intercept decreases with increase 

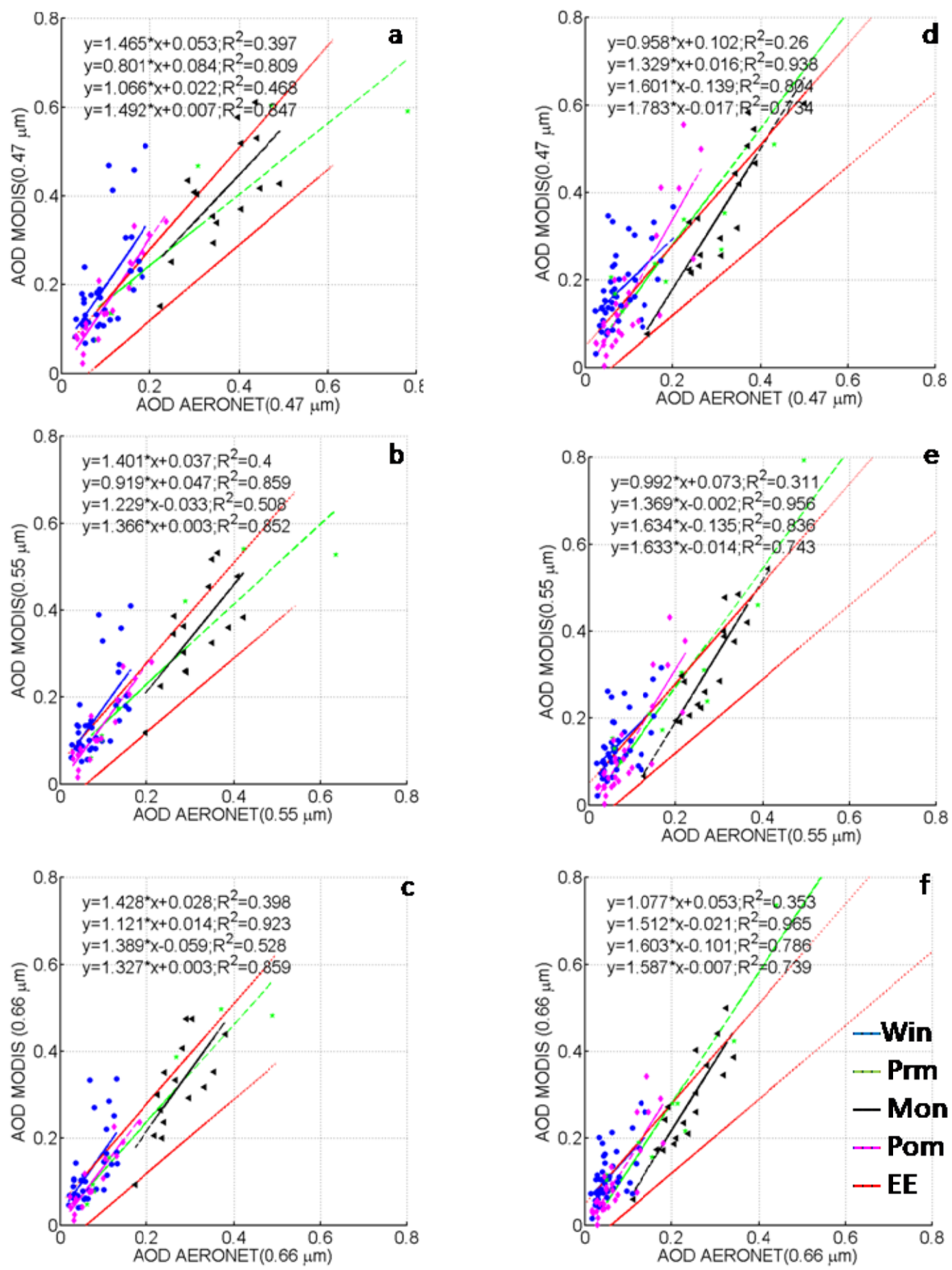

Fig. 4. MODIS-retrieved AOD versus AERONET at Nainital for Aqua (a to c) and Terra (d to f), at $\lambda=0.475,0.55$ and $0.66 \mu \mathrm{m}$. Regression equations are in sequence winter (Win), pre-monsoon (Prm), monsoon (Mon) and post-monsoon (Pom). EE refers to the error envelope per the MODIS uncertainty of $\pm 0.05 \pm 0.15 \tau$, where $\tau$ is AOD.

in wavelength for Gandhi College (Aqua), while Kanpur (Terra) has a reverse trend. Therefore surface reflectancewavelength relationship for MODIS pre-monsoon months is not very clear, especially at Gandhi College as it has poor correlation and high degree of variation in data statistics, as discussed below.

Plotting the pre-launch uncertainty shows that for both the sensors, at all three wavelengths, less than $60 \%$ data are 
Table 2. Data statistics for Gandhi College regression analysis, $m$ and $c$ are the slope and intercept for the linear regression fit, $R^{2}$ is the correlation coefficient, and $N$ is the total data points available. TOT: Total, WIN: Winter, PRM: Pre Monsoon, MON: Monsoon, POM: Post Monsoon.

\begin{tabular}{|c|c|c|c|c|c|c|c|c|}
\hline \multirow[b]{2}{*}{ TOT } & \multicolumn{4}{|c|}{ AQUA } & \multicolumn{4}{|c|}{ TERRA } \\
\hline & $m$ & $c$ & $R^{2}$ & $N$ & $m$ & $c$ & $R^{2}$ & $N$ \\
\hline 475 & 0.647 & 0.091 & 0.519 & 146 & 0.521 & 0.16 & 0.401 & 200 \\
\hline 550 & 0.658 & 0.070 & 0.535 & 146 & 0.528 & 0.136 & 0.4 & 200 \\
\hline 660 & 0.629 & 0.099 & 0.552 & 139 & 0.489 & 0.221 & 0.331 & 199 \\
\hline \multicolumn{9}{|l|}{ WIN } \\
\hline 475 & 0.741 & 0.032 & 0.546 & 16 & 0.289 & 0.372 & 0.178 & 15 \\
\hline 550 & 0.712 & 0.059 & 0.547 & 16 & 0.281 & 0.319 & 0.188 & 15 \\
\hline 660 & 0.431 & 0.186 & 0.493 & 15 & 0.309 & 0.225 & 0.246 & 15 \\
\hline \multicolumn{9}{|l|}{ PRM } \\
\hline 475 & 0.622 & 0.074 & 0.533 & 86 & 0.584 & 0.101 & 0.48 & 125 \\
\hline 550 & 0.625 & 0.063 & 0.519 & 86 & 0.584 & 0.093 & 0.459 & 125 \\
\hline 660 & 0.581 & 0.122 & 0.500 & 80 & 0.446 & 0.251 & 0.293 & 125 \\
\hline \multicolumn{9}{|l|}{ MON } \\
\hline 475 & 0.716 & 0.222 & 0.715 & 15 & 0.591 & 0.283 & 0.453 & 27 \\
\hline 550 & 0.666 & 0.212 & 0.708 & 15 & 0.553 & 0.266 & 0.452 & 27 \\
\hline 660 & 0.656 & 0.217 & 0.671 & 15 & 0.668 & 0.239 & 0.722 & 26 \\
\hline \multicolumn{9}{|l|}{ POM } \\
\hline 475 & 0.424 & 0.220 & 0.305 & 29 & 0.316 & 0.214 & 0.26 & 33 \\
\hline 550 & 0.479 & 0.152 & 0.341 & 29 & 0.316 & 0.177 & 0.239 & 33 \\
\hline 660 & 0.431 & 0.128 & 0.349 & 29 & 0.376 & 0.195 & 0.165 & 33 \\
\hline
\end{tabular}

within the EE envelope. This shows that the retrieval is very poor at Gandhi College. To find out if the major outlier is from a particular season, we checked the outliers above and below the envelope and found that the problem is consistent in all seasons and at all wavelengths for both Aqua and Terra. It is also seen that Gandhi College poses a major challenge to the retrieval process of MODIS, with consistent underestimation $(\sim 0.3)$ for $\mathrm{AOD}>0.5$ at all three wavelengths for both the sensors and in all seasons. Small overestimation $(\sim 0.15)$ for $\mathrm{AOD}<0.25$, for both the sensors, during post-monsoon is also seen at 0.47 and $0.55 \mu \mathrm{m}$. Overestimation is less at $0.66 \mu \mathrm{m}$ in comparison to the other two channels.

The confidence level test was performed for the statistics obtained for Gandhi College. It is seen that for the total available data, the variation at $90 \%$ confidence level is almost equal at every wavelength $(\sim 0.097$ for Aqua). The variation at $90 \%$ confidence level is less for Terra as compared to Aqua. The variation is smallest for $0.55 \mu \mathrm{m}$ channel (0.072), and for the other two it is almost equal $(\sim 0.087)$. For the entire dataset we can say that at Gandhi College the confidence in calculated statistics is $90 \%$, but for seasonal data the confidence level is lower.

\subsubsection{Nainital}

The regression analysis for the total data shows that Terra has a better performance, as compared to that of Aqua, as the correlation is quite better for Terra (see Table 3 ). The cor- relation is seen to improve with increase in wavelength $(\lambda)$, which is not the case in either of the other two sites, Kanpur and Gandhi College. The slope for both Aqua and Terra is nearly one and the intercept is very small. Therefore the assumed model is working fine over Nainital and also the errors due to surface reflectance are low. Also, less variation in surface reflectance owing to the forested mountain slopes, as compared to the agricultural land in Gandhi College, provides better results for Nainital. At Nainital, errors due to surface reflectance decrease with increase in wavelength $(\lambda)$ for both Aqua and Terra.

Figure 4 shows the regression plots for all four seasons at all three wavelengths $(\lambda)$. Seasonal regression analysis shows that winter has very poor correlation for both Aqua as well as Terra. The intercept value is also high, showing that during winter season both sensors suffer from errors due to surface reflectance. Pre-monsoon sees very high correlation for Terra $\left(R^{2}>0.93\right)$ as well as Aqua $\left(R^{2}>0.8\right)$. The surface reflectance contribution is very minimal as the intercept is very small, especially for Terra. Also, an increase in the slope and a decrease in the intercept are seen with increase in wavelength. Post-monsoon shows that Aqua has better performance with respect to Terra. The $R^{2}$ improves with increase in wavelength, with $0.66 \mu \mathrm{m}$ channel as an exception. Very high value of slope $\left(m_{0.47}^{\text {terra }} \sim 1.783\right)$ is seen. Ideally slope should be 1 , but a higher value of slope suggests over prediction in post-monsoon. Considering the fact that MODIS has a tendency of overestimation for low aerosol 
Table 3. Data statistics for Nainital regression analysis, $m$ and $c$ are the slope and intercept for the linear regression fit, $R^{2}$ is the correlation coefficient, and $N$ is the total data points available.

\begin{tabular}{|c|c|c|c|c|c|c|c|c|}
\hline \multirow[b]{2}{*}{ TOT } & \multicolumn{4}{|c|}{ AQUA } & \multicolumn{4}{|c|}{ TERRA } \\
\hline & $m$ & $c$ & $R^{2}$ & $N$ & $m$ & $c$ & $R^{2}$ & $N$ \\
\hline 475 & 0.891 & 0.091 & 0.689 & 78 & 1.199 & 0.053 & 0.831 & 100 \\
\hline 550 & 0.937 & 0.058 & 0.742 & 78 & 1.226 & 0.032 & 0.862 & 100 \\
\hline 660 & 1.070 & 0.032 & 0.802 & 78 & 1.305 & 0.019 & 0.874 & 100 \\
\hline \multicolumn{9}{|l|}{ WIN } \\
\hline 475 & 1.465 & 0.053 & 0.397 & 38 & 0.958 & 0.102 & 0.260 & 43 \\
\hline 550 & 1.4 & 0.037 & 0.4 & 38 & 0.992 & 0.073 & 0.311 & 43 \\
\hline 660 & 1.428 & 0.028 & 0.398 & 38 & 1.077 & 0.053 & 0.353 & 43 \\
\hline \multicolumn{9}{|l|}{ PRM } \\
\hline 475 & 0.801 & 0.084 & 0.809 & 7 & 1.329 & 0.016 & 0.938 & 12 \\
\hline 550 & 0.919 & 0.047 & 0.859 & 7 & 1.369 & -0.002 & 0.956 & 12 \\
\hline 660 & 1.121 & 0.014 & 0.923 & 7 & 1.512 & -0.021 & 0.942 & 12 \\
\hline \multicolumn{9}{|l|}{ MON } \\
\hline 475 & 1.066 & 0.022 & 0.468 & 15 & 1.601 & -0.139 & 0.804 & 17 \\
\hline 550 & 1.229 & -0.033 & 0.508 & 15 & 1.634 & -0.135 & 0.836 & 17 \\
\hline 660 & 1.389 & -0.059 & 0.528 & 15 & 1.603 & -0.101 & 0.786 & 17 \\
\hline \multicolumn{9}{|l|}{ POM } \\
\hline 475 & 1.492 & 0.007 & 0.847 & 18 & 1.783 & -0.017 & 0.734 & 28 \\
\hline 550 & 1.366 & 0.003 & 0.852 & 18 & 1.633 & -0.014 & 0.743 & 28 \\
\hline 660 & 1.327 & 0.003 & 0.859 & 18 & 1.587 & -0.007 & 0.793 & 28 \\
\hline
\end{tabular}

loading (Levy et al., 2010), Nainital having quite low aerosol loading could be suffering from the same problem.

Retrieval at Nainital is well within the EE, which is verified by plotting the uncertainty envelope for the total dataset (Fig. 4). The results show that Nainital has more than twothirds data within the EE, and thus we can safely say that retrieval works fine here, but there is some constant overestimation in winter and post-monsoon. But as more than $70 \%$ data for post-monsoon is within the EE, the retrieval for postmonsoon is not poor. Winter has an over-estimation problem, but this problem decreases at $0.66 \mu \mathrm{m}$ channel.

Similar to Kanpur and Gandhi College, a confidence level test was done at Nainital too. The results show that for the entire dataset Terra shows lower variation, as seen in Kanpur and Gandhi College also. The confidence level in the $R^{2}$ is $90 \%$, as at higher confidence level the variation is large. The variation for the computed $R^{2}$ for Nainital is higher as compared to Kanpur and almost equal to that in Gandhi College. The low sample size for the Nainital dataset can be one of the reasons for high variation in $R^{2}$. During winter season the variation for computed $R^{2}$ is high, and as is the case for the total dataset, Terra has smaller variation. The variation is nearly constant with wavelength. In the pre-monsoon season, variation is less and is smaller for Terra, as for total data at $90 \%$ confidence level. Also, the variation is nearly constant with increase in wavelength. Aqua, however, has a high degree of variation $(\sim 0.25)$ for computed $R^{2}$; the variability is seen to decrease with increase in wavelength. Monsoon has higher level of variation in $R^{2}$ for Aqua, nearly 4 times that of
Terra. In post-monsoon the variation is high for Terra (average $\sim 0.14$ ) for the computed $R^{2}$ and increases with increase in wavelength. Aqua shows lower variation $(\sim 0.09)$ and the variation decreases with increase in wavelength.

Due to the fact that more than two-thirds of data are within the uncertainty envelope, we consider MODIS retrieval unbiased in pristine conditions that are prevalent at Nainital. Also, considering that these retrievals are made for quite low aerosol loading, it is another improvement over the previous collection of MODIS, which had a problem of overestimation for low AOD cases.

\section{Conclusion}

This study presents an examination of MODIS C005 AOD retrieval by comparing with AERONET-measured AOD for different time durations at three different sites: Kanpur (2000-2010), Gandhi College (2005-2010) and Nainital (2008-2010). The results presented here give a more detailed picture with regard to performance of MODIS over the IGP region than any previous study.

At Kanpur, AERONET data show a general trend of decreasing AOD from winters to pre-monsoon, increasing through months of pre-monsoon, decreasing through months of monsoon to post-monsoon, and finally decreasing in the months of post-monsoon to winter (December shows increase). The same is seen at Gandhi College, but AOD is higher, showing that both sites differ in aerosol loading 
(Srivastava et al., 2012). Nainital shows an increase in winter but AOD is low as compared to the other two stations.

1. Kanpur has good correlation with high confidence level for total data and for both the sensors, as was indicated in earlier studies by Jethva et al. Regression analysis shows that Terra performed better than Aqua. Seasonal correlation shows that at Kanpur, winter and postmonsoon have similar performance; correlation worsens with increase in wavelength attributed to finer aerosols. But considering that the retrieval is well within the error limit for both the sensors, with some outliers both above and below the uncertainty envelope belonging to different seasons, we can safely conclude that MODIS retrieval accounts well for the AOD over Kanpur.

2. Gandhi College has poor correlation for both the sensors and also less than $57 \%$ data are within the pre-launch uncertainty. Thus Gandhi College poses a challenge to the MODIS retrieval scheme. Most of the outliers fall below the uncertainty envelope; therefore there is underestimation at Gandhi College for all seasons. The underestimation becomes higher $(\sim 0.3)$ for AOD $>0.5$. The higher underestimation at higher wavelength suggests that the actual SSA value at Gandhi College may be lower than the value assumed by the MODIS algorithm (Ichoku et al., 2003). Small overestimation $(\sim 0.15)$ for $\mathrm{AOD}<0.25$, for both the sensors, during post-monsoon is also seen at 0.47 and $0.55 \mu \mathrm{m}$.

3. Nainital shows very high correlation and much less surface reflectance error. Nainital has more than two-thirds data within the EE, and thus we can safely say that retrieval works fine here. A distinguished feature seen here is that all the outliers fall above the uncertainty envelope, therefore MODIS overestimates, which is the case mainly in winter. Nainital is a relatively clean site and has low AOD; still, more than two-thirds retrieval are within the prelaunch uncertainty. This shows the improved performance of $\mathrm{C} 005$ even in low AOD conditions which was a problem for the earlier collections.

A quality-assured study over the Indian subcontinent showed that correlation is greatly improved if the data with only high QAC are used (Hyer et al., 2011). Thus the entire dataset being provided by the current algorithm is not suitable for use in aerosol modeling. Data from AERONET at Kanpur was used during development of the currently used LUT in the MODIS C005 algorithm and hence the C005 gives good result over Kanpur. Nainital, which is a pristine site, also shows good retrieval by MODIS. However, this is not the case with Gandhi College (a rural area), which suffers possibly due to a misfit in the assumed aerosol model and poor surface parameterization. The large variability in land use and climate over India makes it a site too complex for a single aerosol model to be used over the entire area. Therefore further study with as many sites as possible over the Indian subcontinent would help provide more realistic model for Indian subcontinent.

Acknowledgements. We are thankful to LPDAAC and NASSCOM NASA team for providing the required MODIS data for the current study. We appreciate the efforts of PIs in establishing and maintaining the three AERONET sites in the current study. SNT was supported under the program Changing Water Cycle funded jointly by Ministry of Earth Sciences, India, and Natural Environment Research Council, UK.

Topical Editor P. Drobinski thanks two anonymous referees for their help in evaluating this paper.

\section{References}

Arola, A., Schuster, G., Myhre, G., Kazadzis, S., Dey, S., and Tripathi, S. N.: Inferring absorbing organic carbon content from AERONET data, Atmos. Chem. Phys., 11, 215-225, doi:10.5194/acp-11-215-2011, 2011.

Baxla, S. P., Roy, A. A., Gupta, T., Tripathi, S. N., and Bandyopadhyaya, R.: Analysis of Diurnal and Seasonal Variation of Submicron Outdoor Aerosol Mass and Size Distribution in a Northern Indian City and Its Correlation to Black Carbon, Aerosol and Air Quality Research, 9, 458-469, doi:10.4209/aaqr.2009.03.0017, 2009.

Bellouin, N., Boucher, O., Haywood, J., and Reddy, M. S.: Global estimate of aerosol direct radiative forcing from satellite measurements, Nature, 438, 1138-1141, 2005.

Charlson, R. J., Schwartz, S. E., Hales, J. M., Cess, R. D., Coakley, J. A., Hansen, J. E., and Hofmann, D. J.: Climate Forcing by Anthropogenic Aerosols, Science, 255, 423-430, doi:10.1126/science.255.5043.423, 1992.

Dave, J. V.: Intensity and Polarization of the Radiation Emerging from a Plane-Parallel Atmosphere Containing Monodispersed Aerosols, Appl. Optics, 9, 2673-2684, 1970.

Dey, S. and Tripathi, S. N.: Aerosol direct radiative effects over Kanpur in the Indo-Gangetic basin, northern India: Long-term $(2001 \& \# 8211 ; 2005)$ observations and implications to regional climate, J. Geophys. Res., 113, D04212, doi:10.1029/2007jd009029, 2008.

Dey, S., Tripathi, S. N., Singh, R. P., and Holben, B. N.: Influence of dust storms on the aerosol optical properties over the Indo-Gangetic basin, J. Geophys. Res., 109, D20211, doi:10.1029/2004jd004924, 2004.

Dubovik, O. and King, M. D.: A flexible inversion algorithm for retrieval of aerosol optical properties from Sun and sky radiance measurements, J. Geophys. Res., 105, 20673-20696, doi:10.1029/2000jd900282, 2000.

Dubovik, O., Smirnov, A., Holben, B. N., King, M. D., Kaufman, Y. J., Eck, T. F., and Slutsker, I.: Accuracy assessments of aerosol optical properties retrieved from Aerosol Robotic Network (AERONET) Sun and sky radiance measurements, J. Geophys. Res., 105, 9791-9806, doi:10.1029/2000jd900040, 2000.

Dubovik, O., Sinyuk, A., Lapyonok, T., Holben, B. N., Mishchenko, M., Yang, P., Eck, T. F., Volten, H., Muñoz, O., Veihelmann, B., van der Zande, W. J., Leon, J.-F., Sorokin, M., and Slutsker, I.: Application of spheroid models to account for aerosol particle 
nonsphericity in remote sensing of desert dust, J. Geophys. Res., 111, D11208, doi:10.1029/2005jd006619, 2006.

Dumka, U. C., Moorthy, K. K., Satheesh, S. K., Sagar, R., and Pant, P.: Short-Period Modulations in Aerosol Optical Depths over the Central Himalayas: Role of Mesoscale Processes, Journal of Applied Meteorology and Climatology, 47, 1467-1475, doi:10.1175/2007JAMC1638.1, 2008.

Dumka, U. C., Krishna Moorthy, K., Tripathi, S. N., Hegde, P., and Ram Sagar: Altitude variation of aerosol properties over the Himalayan range inferred from spatial measurements, J. Atmos. Solar-Terr. Phys., 73, 1747-1761, 2011.

Eck, T. F., Holben, B. N., Reid, J. S., Dubovik, O., Smirnov, A., O'Neill, N. T., Slutsker, I., and Kinne, S.: Wavelength dependence of the optical depth of biomass burning, urban, and desert dust aerosols, J. Geophys. Res., 104, 31333-31349, doi:10.1029/1999jd900923, 1999.

Eck, T. F., Holben, B. N., Sinyuk, A., Pinker, R. T., Goloub, P., Chen, H., Chatenet, B., Li, Z., Singh, R. P., Tripathi, S. N., Reid, J. S., Giles, D. M., Dubovik, O., O’Neill, N. T., Smirnov, A., Wang, P., and Xia, X.: Climatological aspects of the optical properties of fine/coarse mode aerosol mixtures, J. Geophys. Res., 115, D19205, doi:10.1029/2010jd014002, 2010.

Evans, K. F. and Stephens, G. L.: A new polarized atmospheric radiative transfer model, J. Quant. Spectr. Radiat. T., 46, 413-423, 1991.

Gatebe, C. K., King, M. D., Si-Chee, T., Ji, Q., Arnold, G. T., and Li, J. Y.: Sensitivity of off-nadir zenith angles to correlation between visible and near-infrared reflectance for use in remote sensing of aerosol over land, Geoscience and Remote Sensing, IEEE Transactions on, 39, 805-819, 2001.

Giles, D., Holben, B. N., Tripathi, S. N., Eck, T., Newcomb, W., Slutsker, I., Dickerson, R., Thompson, A., Mattoo, S., Wang, S.-H., Singh, R., Sinyuk, A., and Schafer, J.: Aerosol Properties over the Indo-Gangetic Plain: A Mesoscale Perspective from the TIGERZ Experiment, J. Geophys. Res., 116, D18203, doi:10.1029/2011JD015809, 2011.

Habib, G., Venkataraman, C., Chiapello, I., Ramachandran, S., Boucher, O., and Shekar Reddy, M.: Seasonal and interannual variability in absorbing aerosols over India derived from TOMS: Relationship to regional meteorology and emissions, Atmos. Environ., 40, 1909-1921, doi:10.1016/j.atmosenv.2005.07.077, 2006.

Holben, B. N., Eck, T. F., Slutsker, I., Tanré, D., Buis, J. P., Setzer, A., Vermote, E., Reagan, J. A., Kaufman, Y. J., Nakajima, T., Lavenu, F., Jankowiak, I., and Smirnov, A.: AERONET - A Federated Instrument Network and Data Archive for Aerosol Characterization, Remote Sens. Environ., 66, 1-16, doi:10.1016/s0034-4257(98)00031-5, 1998.

Hyer, E. J., Reid, J. S., and Zhang, J.: An over-land aerosol optical depth data set for data assimilation by filtering, correction, and aggregation of MODIS Collection 5 optical depth retrievals, Atmos. Meas. Tech., 4, 379-408, doi:10.5194/amt-4-379-2011, 2011.

Ichoku, C., Chu, D. A., Mattoo, S., Kaufman, Y. J., Remer, L. A., Tanré, D., Slutsker, I., and Holben, B. N.: A spatio-temporal approach for global validation and analysis of MODIS aerosol products, Geophys. Res. Lett., 29, 8006, doi:10.1029/2001g1013206, 2002.
Ichoku, C., Remer, L. A., Kaufman, Y. J., Levy, R., Chu, D. A., Tanré, D., and Holben, B. N.: MODIS observation of aerosols and estimation of aerosol radiative forcing over southern Africa during SAFARI 2000, J. Geophys. Res., 108, 8499, doi:10.1029/2002jd002366, 2003.

Jethva, H., Satheesh, S. K., and Srinivasan, J.: Assessment of second-generation MODIS aerosol retrieval (Collection 005) at Kanpur, India, Geophys. Res. Lett., 34, L19802, doi:10.1029/2007g1029647, 2007.

Kaufman, Y. J., Tanré, D., Remer, L. A., Vermote, E. F., Chu, A., and Holben, B. N.: Operational remote sensing of tropospheric aerosol over land from EOS moderate resolution imaging spectroradiometer, J. Geophys. Res., 102, 17051-17067, doi:10.1029/96jd03988, 1997a.

Kaufman, Y. J., Wald, A. E., Remer, L. A., Bo-Cai, G., Rong-Rong, L., and Flynn, L.: The MODIS 2.1-mum channel-correlation with visible reflectance for use in remote sensing of aerosol, Geoscience and Remote Sensing, IEEE Transactions on, 35, 12861298, 1997b.

King, M. D., Kaufman, Y. J., Menzel, W. P., and Tanre, D.: Remote sensing of cloud, aerosol, and water vapor properties from the moderate resolution imaging spectrometer (MODIS), Geoscience and Remote Sensing, IEEE Transactions on, 30, 2-27, 1992.

King, M. D., Kaufman, Y. J., Tanré, D., and Nakajima, T.: Remote Sensing of Tropospheric Aerosols from Space: Past, Present, and Future, B. Am. Meteorol. Soc., 80, 2229-2259, doi:10.1175/1520-0477(1999)080<2229:RSOTAF > 2.0.CO;2, 1999.

King, M. D., Menzel, W. P., Kaufman, Y. J., Tanre, D., Bo-Cai, G., Platnick, S., Ackerman, S. A., Remer, L. A., Pincus, R., and Hubanks, P. A.: Cloud and aerosol properties, precipitable water, and profiles of temperature and water vapor from MODIS, Geoscience and Remote Sensing, IEEE Transactions on, 41, 442458, 2003.

Levy, R. C., Remer, L. A., and Kaufman, Y. J.: Effects of neglecting polarization on the MODIS aerosol retrieval over land, Geoscience and Remote Sensing, IEEE Transactions on, 42, 25762583, 2004.

Levy, R. C., Remer, L. A., Martins, J. V., Kaufman, Y. J., Plana-Fattori, A., Redemann, J., and Wenny, B.: Evaluation of the MODIS Aerosol Retrievals over Ocean and Land during CLAMS, J. Atmos. Sci., 62, 974-992, doi:10.1175/JAS3391.1, 2005.

Levy, R. C., Remer, L. A., Mattoo, S., Vermote, E. F., and Kaufman, Y. J.: Second-generation operational algorithm: Retrieval of aerosol properties over land from inversion of Moderate Resolution Imaging Spectroradiometer spectral reflectance, J. Geophys. Res., 112, D13211, doi:10.1029/2006jd007811, 2007.

Levy, R. C., Remer, L. A., Kleidman, R. G., Mattoo, S., Ichoku, C., Kahn, R., and Eck, T. F.: Global evaluation of the Collection 5 MODIS dark-target aerosol products over land, Atmos. Chem. Phys., 10, 10399-10420, doi:10.5194/acp-10-10399-2010, 2010.

Misra, A., Jayaraman, A., and Ganguly, D.: Validation of MODIS derived aerosol optical depth over Western India, J. Geophys. Res., 113, D04203, doi:10.1029/2007jd009075, 2008.

Nair, V. S., Moorthy, K. K., Alappattu, D. P., Kunhikrishnan, P. K., George, S., Nair, P. R., Babu, S. S., Abish, B., Satheesh, S. K., Tripathi, S. N., Niranjan, K., Madhavan, B. L., Srikant, V., Dutt, 
C. B. S., Badarinath, K. V. S., and Reddy, R. R.: Wintertime aerosol characteristics over the Indo-Gangetic Plain (IGP): Impacts of local boundary layer processes and long-range transport, J. Geophys. Res., 112, D13205, doi:10.1029/2006jd008099, 2007.

Remer, L. A., Wald, A. E., and Kaufman, Y. J.: Angular and seasonal variation of spectral surface reflectance ratios: implications for the remote sensing of aerosol over land, Geoscience and Remote Sensing, IEEE Transactions on, 39, 275-283, 2001.

Remer, L. A., Kaufman, Y. J., Tanré, D., Mattoo, S., Chu, D. A., Martins, J. V., Li, R.-R., Ichoku, C., Levy, R. C., Kleidman, R. G., Eck, T. F., Vermote, E., and Holben, B. N.: The MODIS Aerosol Algorithm, Products, and Validation, J. Atmos. Sci., 62, 947-973, doi:10.1175/JAS3385.1, 2005.

Remer, L. A., Kleidman, R. G., Levy, R. C., Kaufman, Y. J., Tanré, D., Mattoo, S., Martins, J. V., Ichoku, C., Koren, I., Yu, H., and Holben, B. N.: Global aerosol climatology from the MODIS satellite sensors, J. Geophys. Res., 113, D14S07, doi:10.1029/2007jd009661, 2008.

Seinfeld, J. H. and Pandis, S. N.: Atmospheric chemistry and physics: from air pollution to climate change, Publisher: New York: Wiley, A Wiley-Interscience Publication, ISBN: 0471178152, 1998.

Sharma, M., Kiran, Y. N. V. M., and Shandilya, K. K.: Investigations into formation of atmospheric sulfate under high PM10 concentration, Atmos. Environ., 37, 2005-2013, doi:10.1016/s13522310(03)00005-0, 2003.

Singh, R. P., Dey, S., Tripathi, S. N., Tare, V., and Holben, B.: Variability of aerosol parameters over Kanpur, northern India, J. Geophys. Res., 109, D23206, doi:10.1029/2004jd004966, 2004.

Solomon, S., Qin, D., Manning, M., Chen, Z., Marquis, M., Averyt, K. B., Tignor, M., and Miller, H. L. (Eds.): Contribution of Working Group I to the Fourth Assessment Report of the Intergovernmental Panel on Climate Change, Cambridge University Press, 996 pp., 2007.
Srivastava, A. K., Tiwari, S., Devara, P. C. S., Bisht, D. S., Srivastava, Manoj K., Tripathi, S. N., Goloub, P., and Holben, B. N.: Pre-monsoon aerosol characteristics over the Indo-Gangetic Basin: implications to climatic impact, Ann. Geophys., 29, 789804, doi:10.5194/angeo-29-789-2011, 2011.

Srivastava, A. K., Tripathi, S. N., Dey, S., Kanawade, V. P., and Tiwari, S.: Inferring aerosol types over the Indo-Gangetic Basin from ground based sunphotometer measurements, Atmos. Res., 109-110, 64-75, doi:10.1016/j.atmosres.2012.02.010, 2012.

Tripathi, S. N., Dey, S., Chandel, A., Srivastava, S., Singh, Ramesh P., and Holben, B. N.: Comparison of MODIS and AERONET derived aerosol optical depth over the Ganga Basin, India, Ann. Geophys., 23, 1093-1101, doi:10.5194/angeo-23-10932005, 2005a.

Tripathi, S. N., Dey, S., Tare, V., Satheesh, S. K., Lal, S., and Venkataramani, S.: Enhanced layer of black carbon in a north Indian industrial city, Geophys. Res. Lett., 32, L12802, doi:10.1029/2005gl022564, 2005b.

Tripathi, S. N., Tare, V., Chinnam, N., Srivastava, A. K., Dey, S., Agarwal, A., Kishore, S., Lal, R. B., Manar, M., Kanwade, V. P., Chauhan, S. S. S., Sharma, M., Reddy, R. R., Gopal, K. R., Narasimhulu, K., Reddy, L. S. S., Gupta, S., and Lal, S.: Measurements of atmospheric parameters during Indian Space Research Organization Geosphere Biosphere Programme Land Campaign II at a typical location in the Ganga basin: 1. Physical and optical properties, J. Geophys. Res., 111, D23209, doi:10.1029/2006jd007278, 2006. 